\title{
HEARING HANDICAP IN OLDER ADULTS: A MULTI-CENTER STUDY
}

\author{
Gul-e-Zahra, Ghulam Saqulain*, Nazia Mumtaz** \\ Yusra General Hospital, Islamabad Pakistan, *Capital Hospital, Islamabad Pakistan, **Riphah International University, Lahore Pakistan
}

\section{ABSTRACT}

Objective: To determine the level of hearing handicap and its age and gender association in older adults.

Study Design: Cross sectional analytical study.

Place and Duration of Study: Study conducted at Ear, Nose \& Throat outpatients of Yusra General Hospital, National Institute of Rehabilitation Medicine Islamabad and Cantonment General Hospital Rawalpindi, from Jul to Sep 2017.

Methodology: We recruited two hundred cases of self-reported hearing difficulty, using non-probability consecutive sampling, who fulfilled inclusion criteria. After recording demographic details including history, subjects were screened by the Screening Version of Hearing Handicap Inventory for the Elderly (HHIE-S). Followed by otoscopy and pure tone audiometry. Analysis was done using SPSS-24.

Results: Study revealed 133 (65.5\%) males and 67 (33.5\%) females with mean age of $65.45 \pm 7.50$ years. Out of 179 (89.5\%) had significantly high level of hearing handicap with HHIE-S score $>43$, while $21(10.5 \%)$ revealed mild to moderate handicap with score of 17-42. Hearing handicap was significantly associated with aging $(p<0.001)$, while no significant gender association was noted. Hearing loss was mainly of sensory-neural type 192 (96\%).

Conclusion: In older adults with self-reported hearing loss, high level of hearing handicap was present in majority (89.5\%) and mild to moderate in $10.5 \%$, with significant association with aging and hearing loss was predominantly sensory- neural type.

Keywords: Aging, Age related hearing loss, Hearing loss, Hearing handicap, Older adults, Prevalence, Quality of life.

How to Cite This Article: Zahra GE, Saqulain G, Mumtaz N. Hearing Handicap in Older Adults: A Multi-Center Study. Pak Armed Forces Med J 2021; 71 (Suppl-3): S590-593. Doi: https://doi.org/10.51253/pafmj.v1i1.3137

This is an Open Access article distributed under the terms of the Creative Commons Attribution License (https://creativecommons.org/licenses/by-nc/4.0/), which permits unrestricted use, distribution, and reproduction in any medium, provided the original work is properly cited.

\section{INTRODUCTION}

Impaired hearing is a common issue in older adults having a prevalence of $25.7 \%$, with age-related hearing loss (AHL) being the commonest etiology. ${ }^{1}$ AHL is a degenerative condition and characterized by sensori-neural hearing loss (SNHL). ${ }^{2}$ Hearing impairmentcauses significant deterioration in quality of life (QOL)and results in communicational difficulties and more social isolation in elderly resulting in handicaps. ${ }^{3}$ Therefore management is a significant public health.

AHL results from simple degenerative process occurring with age, a number of risk factors are incriminated in causation including aging of cochlea, noise exposure, genetic predisposition, and co-morbidities like smoking and atherosclerosis and genetic factors, ${ }^{4}$ which may explain the onset, degree and variations in HL in the older adults. Hearing loss (HL) is independently related to poor physical activity henceregular exercise has been noted to slow its progression. ${ }^{5}$

Hearing handicap is a disastrous situation associated with hearing impairment in the older adults, though level of hearing impairment in all elders may not be perceived socially and emotionally in day to

Correspondence: Dr Ghulam Saqulain, HOD \& Prof of Otolaryngology \& CDA Cochlear Implant Centre, Capital Hospital PGMI, CDA Islamabad Pakistan day life as disabling. ${ }^{6}$

Hearing loss in older adultssignificantly impacts QOL of millions of aging individualsand is more commonly seen as age advances, ${ }^{7}$ with two thirds of adults aged 70 and above affected in United States alone. ${ }^{8}$ Hence it is important to prevent, timely detect and manage as well as mitigate hearing handicap and its impact on families of hearing impaired. ${ }^{9}$ There is dearth of literature on hearing handicapin Pakistan though some authors have studied hearing impairment as a whole, ${ }^{10}$ without focusing on older adults. Therefore, no organized, screening, prevention, treatment and rehabilitation program for the older population facing hearing impairment are in place, resulting in increasing burden of disability.

Therefore the current research focused to determine the level of hearing handicap and its age and gender association in the older adults. This research could be used as a significant reference and base supporting initiativesfor future research and help improve QOL of affected, by timely planning management and rehabilitation of this neglected community.

\section{METHODOLOGY}

This was a cross sectional analytical study conducted in the twin cities of Rawalpindi and Islamabad at ENT outpatient clinics of National Institute of 
Rehabilitation Medicine (NIRM), Islamabad; Yusra and Cantonment General Hospitals, Rawalpindi, Pakistan, using non-probability consecutive sampling technique, to determine the level of hearing handicap and its age and gender association in older adults in Rawalpindi Islamabad region, from July 2017 to September, 2017.

A sample size of 377 cases of self-reported HL was recruited after calculating using Raosoft calculator with 5\% margin of error, 95\% confidence level and a population of 20000 with $50 \%$ response distribution. Those who could not properly fill the questionaire were excluded from the study, leaving behind a sample of 200 eligible cases who fulfilled the selection criteria and consented for inclusion.

Inlcusion Criteria: Cases with self-reported hearing difficulty, of both genders, aged 50-80 years, residing in the area of Rawalpindi \& Islamabad.

Exlusion Criteria: Cases with obstructive \& inflammatory pathologies of outer and middle ear, known cases of otosclerosis, Meniere's, Acoustic neuroma and cases with noise exposure.

The sample was subjected to Screening version of Hearing Handicap Inventory for the Elderly (HHIE-S), developed by Ventry and Weinstein and validated and found easy and reliable to use by Oberg 11 to identify older adults with HL/hearing handicap. This was followed by pure tone audiometry (PTA). Before institution of HHIE-S screening, history was recorded on hospital history sheets in a confidential setting including duration of HL, treatment history, and comorbidities. Latercareful physical ear examination was done including otoscopy to rule out any obstructive and inflammatory pathology. HHIE-S questionaire includes 25 questions to evaluate emotional and social issues related to hearing loss. One of three responses, "yes", "sometimes" or "no", was scored as 4, 2 or 0 , respectively, according to HHIE-S scoring system. PTA was performed in sound proof roomwith a audiometer model MAICO MA 51 and made in Germany. Pure tone thresholds were recorded at 250, 500, 1000, 2000, 4000 \& $8000 \mathrm{~Hz}$.

Data collectedwas analyzed using SPSS-24. Age was presented by Mean \pm SD and categorical variables were presented by frequency and percentage. Chisquare test was used to detect association between variables and $p$-value $\leq 0.05$ was considered significant.

\section{RESULTS}

Sample population revealed $133(66.5 \%)$ males and $67(33.5 \%)$ females and an age range of $50-80$ years and mean age of $65.45 \pm 7.5$ years (figure). Age group distribution (Table-I), revealed highest frequency of 66-70 years (24.5\%), with 61-65 age being second commonest.

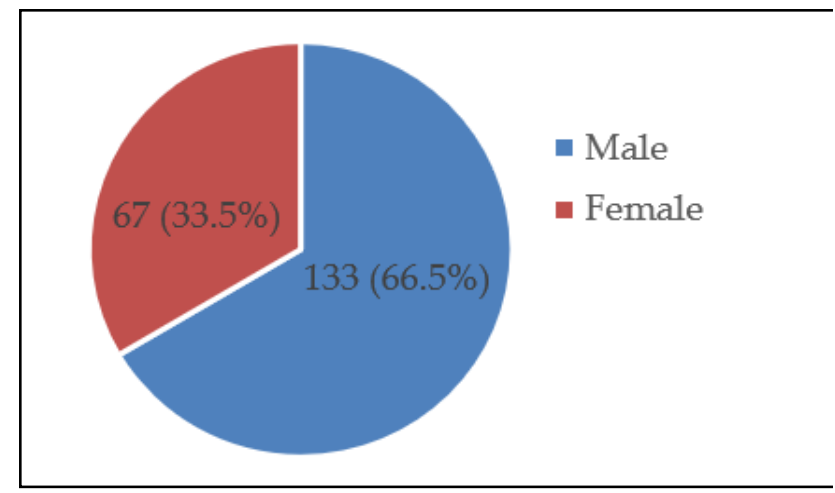

Figure: Gender distribution $(n=200)$.

Table-I: Age distribution of the study sample $(n=200)$.

\begin{tabular}{|c|c|c|}
\hline \multicolumn{2}{|c|}{ Characteristics } & Value $(n=200)$ \\
\hline Age (Years) & Mean \pm SD & $65.45 \pm 7.50$ \\
\hline Age & $50-55$ years & $22(11 \%)$ \\
\hline Groups & $56-60$ years & $37(18.5 \%)$ \\
\hline & $61-65$ years & $41(20.5 \%)$ \\
\hline & $66-70$ years & $49(24.5 \%)$ \\
\hline & $71-75$ years & $32(16 \%)$ \\
\hline & $76-80$ years & $19(9.5 \%)$ \\
\hline
\end{tabular}

Table-II showed that 179 (89.5\%) cases had a score of $\geq 43$ indicating severe hearing handicap and $21(10.5 \%)$ revealed score of $17-42$ i.e., mild to moderate handicap. There was much higher score in male compare to female indicating that age related hearing loss was more common in male gender, however the diffe-rence was not statistically significant $(p=0.147)$ (Table-II).

To determine the level of hearing handicap, the percentage of the HHIE-S basedself-identified hearing handicap and PTA based HL was studied by dividing the subjects into age groups. It was noted (Table-II) that SNHL and hearing handicap were more common in higher age groups indicating higher prevalence with advancing age with maximum percentage of cases reported with HL in the 66-70 years age group. However in this study the percentage of cases after 70 years of age dropped. Also it was noted that few cases of conductive hearing loss were present in the younger age groups with higher frequency of age related SNHL with advancing age.

A statistically significant association of HHIEscore with age with positive correlation was present, while difference for gender and HHIE-Score was not statistically significant (Table-II). 
Hearing Handicap in Older Adults

Table-II: Age \& gender distribution versus handicap severity (HHIE-S Score) \& cases of audiometry proven hearing loss distribution: cross tabulation\& chi-square correlation $(n=200)$

\begin{tabular}{|c|c|c|c|c|c|c|}
\hline \multirow{3}{*}{ Variable } & \multirow{3}{*}{$\begin{array}{c}\text { Variable } \\
\text { Characteristics }\end{array}$} & \multicolumn{2}{|c|}{ Audiometry } & \multicolumn{2}{|c|}{ Handicap Severity Score } & \multirow{2}{*}{$\begin{array}{c}\text { Chi-Square } \\
X^{2}(p \text {-value })\end{array}$} \\
\hline & & SNHL & CHL & Score: $17-42$ & Score: $>43$ & \\
\hline & & n (\%) & n (\%) & n (\%) & n (\%) & \\
\hline \multirow{7}{*}{$\begin{array}{l}\text { Age Group } \\
\text { (Years) }\end{array}$} & $50-55$ & $18(9)$ & $4(2)$ & $14(7)$ & $8(4)$ & \multirow{6}{*}{$81.952(0.000)$} \\
\hline & $56-60$ & $34(17)$ & $3(1.5)$ & $6(3)$ & $31(15.5)$ & \\
\hline & $61-65$ & $40(20)$ & $1(0.5)$ & $1(.5)$ & $40(20)$ & \\
\hline & $66-70$ & $49(24.5)$ & - & - & $49(24.5)$ & \\
\hline & $71-75$ & $32(16)$ & - & - & $32(16)$ & \\
\hline & $76-80$ & $19(9.5)$ & - & - & $19(9.5)$ & \\
\hline & Total & $192(96)$ & $8(4 \%)$ & $21(10.5)$ & $179(89.5 \%)$ & \\
\hline \multirow{3}{*}{ Gender } & Male & 129 (67.19) & $4(2)$ & $11(8.27)$ & $122(91.73)$ & \multirow{2}{*}{$2.100(0.147)$} \\
\hline & Female & $63(32.81)$ & $4(2)$ & $10(14.93)$ & $57(85.07)$ & \\
\hline & Total & $192(96)$ & $8(4)$ & $21(10.5)$ & $179(89.5)$ & \\
\hline
\end{tabular}

(Note: $n=$ Frequency, \%=Percentage)

\section{DISCUSSION}

The current study comprised of self-reported cases of hearing loss with an age range of 50-80 years and Mean age of $65.45 \pm 7.50$ years. HHIE-S results revealed that $179(89.5 \%)$ had severe hearing handicap with a score of $>43$, while $21(10.5 \%)$ revealed mild to moderate handicap with score of 17-42. In contrast in a study by Servidoni \& Conterno in which sample were collected from an otolaryngology clinic prevalence of mild to moderate handicap was $47.1 \%$ and severe handicap was present in $29 \%$ and remaining population had no handicap. ${ }^{12}$ The higher frequency of severe HL and handicap in our setup might be due to dearth of diagnostic and rehabilitation facilities.

Hearing handicap was significantly associated with aging $(p<0.001)$ and was mainly sensory-neural in $192,96 \%$ indicating that age related hearing loss was the main etiology. Also study revealed a male preponderance with $66.5 \%$ (133) males and 33.5\% (67) females, however the gender association with HHIE-S score did not reveal any statistically significant association. AHL is a neurodegenerative process and the commonest cause of hearing impairment, which can also result in psychological distress due to compromised QOL. ${ }^{13}$ AHL has a very high prevalence affecting around $40 \%$ of those above 65 years of age, with Homans et al, reporting a prevalence of $33 \%$ in males and $29 \%$ females of hearing loss above $35 \mathrm{~dB}$ in cases 65 years and above in a large cohort study. ${ }^{7}$ In the present study also AHL was more prevalent in males with male female ratio of 1.98:1. Elahi et al, reported a prevalence of hearing loss of $7.9 \%$ inchildren $5-15$ years of age, ${ }^{14}$ but localstatistics regarding hearing handicap and hearing loss in the older adults are lacking, which was the stimulus for this study. Clinically, progression of AHL is variable, the typical course being, beginning in 6th decade of a slow, symmetric but persistent decrease in hearing threshold with age in the high-frequency range..$^{15}$ Age limit for AHL is not well defined however, Roth et al, in their review article noted a lower limit of 60 years for AHL. 16

The results of our study revealed there was association of hearing loss/handicap with advancing age, as seen in table-II, with frequency increasing with age from $11 \%$ in $50-55$ years age groupto a maximum of $24.5 \%$ in $66-70$ years age group. However the frequency dropped in age group 71-75 (16\%) and 76-80 $(9.5 \%)$. Literature review revealed heterogeneity in available international data making it difficult to make a proper quantitative overview of prevalence of HL over age. However studies were noted to reflect an increase of hearing loss with increasing age, with male preponderance. ${ }^{17}$ In a Saudi Arabian study Al-Ruwali et al, reported higher prevalence of HL/ handicap with advancing age on the basis of HHIE-S screening with prevalence of $4.7 \%$ at $41-45$ years age, $10.17 \%$ at $46-50$ and 38.35 in $71-75$ years age group. ${ }^{18}$ Gates et al, ${ }^{19}$ also reported higher prevalence of hearing loss with increasing age from 6th to 9 th decade with $25-40 \%$ above 65 years, $50 \%$ above 75 years and $80 \%$ above 85 years age. However this did not differ by gender. ${ }^{19}$ It is interesting to note that the very high prevalence seen in the $>75$ years and $>85$ years age group in Framingham cohort study by Gates et al. ${ }^{19}$ and Walling et al. ${ }^{20}$ was not present in our study. WHO survey of the year 2017 in Pakistan revealed a life expectancy of 65.5 years for males and 67.5 years for female. This could be the cause of high frequency of HL/handicap up to age group of 66-70 and less frequency beyond this age. In a review article, Roth et al16, noted that for Europe the prevalence of AHR was 30\% for males and $20 \%$ for females at age of 70 years and $55 \%$ males and $45 \%$ 
females at age of 80 years which is in contrast to our study. This fact is of importance, since increase in life expectancy of our population could result inincreased burden of HL/handicap in Pakistan. According to Mathers \& Luycar, AHL was projected to be one of the top 15 causes of burden of disease by year $2030 .{ }^{21}$

Since prevention, early diagnosis and intervention can enhance QOL and reduce the burden of disability, therefore, it wasimperative to determine the frequency of HL and hearing handicap in our elderly population, to obtain basic statistical data about magnitude of problem in our setup. This can also help develop a strategy for adult hearing screening, its diagnosis and plan management and rehabilitation.

\section{CONCLUSIONS}

In older adults with self-reported HL, high level of hearing handicap was present in majority (89.5\%) and mild to moderate in $10.5 \%$, with significant association with aging and hearing loss was predominantly sensory-neural type. Therefore this elderly population of age beyond 50 years requires screening, assessment and treatment along with rehabilitative measures to reduce the burden of disability.

\section{Conflict of Interest: None.}

\section{Authors' Contribution}

GEZ: Data collection, statistical analysis \& Interpretation, GS: Manuscript writing, methodology, literture review \& responsible for publication, NM: Conception of work \& critical revision of manuscript.

\section{REFERENCES}

1. Moraes CKG, Pacheco FA. Prevalence of self-reported hearing loss and associated risk factors among the elderly in Manaus: a population-based study. Rev. CEFAC 2015; 17(6 ): 1946-1956.

2. Pearlman RC. Presbycusis: the need for a clinical definition. Am J Otol 1982; 3(3): 183-186.

3. Mick P , Kawachi I, Lin FR. The association between hearing loss and social isolation in older adults. Otolaryngol Head Neck Surg 2014; 150(3): 378-384.

4. Yamasoba T, Lin FR, Someya S, Kashio A, Sakamoto T, Kondo K. Current concepts in age-related hearing loss: epidemiology and mechanistic pathways. Hear Res 2013; 303(1): 30-38.

5. Han C, Ding D. Effects of Long-Term Exercise on Age-Related Hearing Loss in Mice. J Neur 2016; 36(44): 11308-11319.
6. Chang HP, Ho CY, Chou P. The factors associated with a selfperceived hearing handicap in elderly people with hearing impairment-results from a community-based study. Ear Hear 2009; 30(5): 576-583.

7. Homans NC, Metselaar RM, Dingemanse JG, van der Schroeff MP, Brocaar MP, Wieringa MH et al. Prevalence of age-related hearing loss, including sex differences, in older adults in a large cohort study. Laryn 2017; 127(3): 725-730.

8. Lin FR, Thorpe R, Gordon-Salant S, Ferrucci L. Hearing loss prevalence and risk factors among older adults in the united states. J Gerontol A Biol Sci Med Sci 2011; 66(5): 582-590.

9. Davis A, McMahon CM, Pichora-Fuller KM, Russ S, Lin F, Olusanya BO, et al. Aging and hearing health: the life-course approach, The Gerontol 2016; 56(2): 256-267.

10. Musani MA, Rauf A, Ahsan M, Khan FA. Frequency and causes of hearing impairment in tertiary care center. J Pak Med Assoc 2011; 61(2): 141-144.

11. Oberg M. Validation of the swedish hearing handicap inventory for the elderly (screening version) and evaluation of its effect in hearing Aid rehabilitation. Trends Hear 2016; 20(2): 2331216516639234.

12. Servidoni $A B$, Conterno LO. Hearing loss in the elderly: is the hearing handicap inventory for the elderly - screening version effective in diagnosis when compared to the audiometric test?. Int Arch Otorhinolaryngol 2018; 22(1): 1-8.

13. Corna LM , Wade TJ, Streiner DL, Cairney J. Transitions in hearing impairment and psychological distress in older adults. Can J Psych 2009; 54(8): 518-525.

14. Elahi MM, Elahi F, Elahi A, Elahi SB. Paediatric hearing loss in rural Pakistan. J Otolaryngol 1998; 27(6): 348-53.

15. Yang $\mathrm{CH}$, Schrepfer T, Schacht J. Age-related hearing impairment and the triad of acquired hearing loss. Front Cell Neur 2015; 9(1): 276-280.

16. Roth TN, Hanebuth D, Probst R. Prevalence of age-related hearing loss in Europe: a review. Eur Arch Otorhinolaryngol 2011; 268(8): 1101-1107.

17. Cruickshanks KJ , Wiley TL, Tweed TS, Klein BE, Klein R, MaresPerlman JA, et al. Prevalence of hearing loss in older adults in Beaver Dam, Wisconsin. The Epidemiology of Hearing Loss Study. Am J Epidemiol 1998; 148(9): 879-886.

18. Al-Ruwali N, Hagr A. Prevalence of Presbycusis in the Elderly Saudi Arabian Population. JTU Med Sci 2010; 5(1): 21-26.

19. Gates GA, Cooper JC Jr, Kannel WB, Miller NJ. Hearing in the elderly: the Framingham cohort, 1983-1985. Part I. Basic audiometric test results. Ear Hear 1990; 11(4): 247-256.

20. Walling AD, Dickson GM. Hearing Loss in Older Adults. Am Fam Phy 2012; 85(12): 1150-1156.

21. Mathers CD, Loncar D. Projections of global mortality and burden of disease from 2002 to 2030. PLoS Med 2006; 3(11): e442. 